\title{
CHILE FRENTE A LA RECESIÓN MUNDIAL DE 2009*
}

\author{
José De Gregorio
}

El mundo está atravesando una severa crisis. Chile, pese a mostrar gran solidez en su sistema financiero, no puede estar al margen. Este artículo comienza con una discusión sobre los efectos de la política monetaria en los precios de activos y la estabilidad financiera. Luego se discuten los efectos de la crisis sobre la inflación y la actividad. La primera pasó de aumentos masivos e inesperados, a fuertes disminuciones por ampliación de holguras y caída en los precios internacionales de los productos básicos. Los efectos sobre la actividad se pueden explicar por el ciclo económico interno, efectos reales y financieros de la crisis internacional y la crisis de confianza global. Finalmente, se discuten las distintas políticas implementadas por el Banco Central para asegurar sus objetivos de inflación y funcionamiento de los sistemas de pago interno y externo, entre los que destaca el significativo relajamiento monetario.

Palabras clave: Política monetaria; bancos centrales; inflación; ciclos. Recibido: marzo de 2009; aceptado: abril de 2009.

José De Gregorio. Presidente del Banco Central de Chile.

* Una versión preliminar se presentó en el seminario "Los Temas del 2009”, organizado por el Instituto de Políticas Públicas Expansiva-UDP y Libertad y Desarrollo, Santiago, 20 de marzo. Agradezco los valiosos comentarios y colaboración de Mariana García y Enrique Orellana.

Estudios Públicos, 113 (verano 2009). 


\section{E}

mundo está en una severa crisis, y todas las economías, en diversos grados, están siendo afectadas por la caída del producto en el mundo desarrollado. Lo que partió como una crisis focalizada en el mercado inmobiliario de Estados Unidos se transmitió con fuerza al resto del sistema financiero de los países desarrollados y está afectando de manera significativa, y por diversas vías, la actividad a nivel mundial. De hecho, si hay algo que llama la atención, es el grado de sincronización que la crisis muestra alrededor del mundo.

Como resultado de ello, hoy enfrentamos un panorama muy complejo. Sólo en septiembre del año pasado, cuando todavía se estimaba que la crisis era un problema que afectaría mayormente a los mercados financieros desarrollados, las proyecciones de consenso preveían que el mundo (medido a precios de mercado) crecería 2,5\% durante este año. En marzo, las estimaciones de consenso prevén una caída del PIB mundial de 1,6\%. Es decir, en seis meses, las proyecciones de crecimiento mundial para el 2009 han caído en más de cuatro puntos porcentuales (Tabla $\mathrm{N}^{\circ} 1$ ).

De este modo, después de haber crecido a un promedio cercano a 3\% (a precios de mercado) durante esta década, el PIB mundial se contraerá, algo que no ocurrió ni siquiera durante el shock petrolero de los setenta ni en la crisis de principios de los ochenta. Incluso, el crecimiento mundial medido a paridad del poder de compra (que les da mayor peso a los países en desarrollo, como China, que crecen más rápido) será negativo este año. Esto nunca se había observado en el período de la posguerra.

Como es obvio y como también lo hemos recalcado insistentemente desde el comienzo de este período, nuestra economía no ha estado al margen de esta crisis global. Aun cuando nuestro sistema financiero ha demostrado una saludable solidez, a partir del último trimestre del año pasado se han sentido los efectos de la crisis sobre el sector real. Esto representa un importante desafío para las políticas macroeconómicas, pues son ellas las llamadas a mitigar el impacto de la crisis y, a su vez, a abrir los espacios para una recuperación más temprana que la del resto de mundo. Nuestra economía está sana. Tiene un sistema financiero sólido y una fuerte posición fiscal y de reservas internacionales, las que permiten enfrentar escenarios de financiamiento mucho más severos que los actuales y, además, generar un impulso fiscal contracíclico de gran envergadura. Tenemos un esquema de flotación cambiaria que facilita el ajuste a la menor demanda externa y no estamos atados por camisas de fuerza cambiarias que limiten los ajustes, con dañinas consecuencias para la actividad y el empleo. Por último, las perspectivas inflacionarias han permitido un aumento sustancial del impul- 
TABLA N ${ }^{\circ}$ 1: $\quad$ PROYECCIONES DE CRECIMIENTO PARA EL 2009

(PIB medido a precios de mercado, porcentaje)

\begin{tabular}{lccc}
\hline & Sep. 2008 & Dic. 2008 & Marz. 2009 \\
\hline Mundo & 2,5 & 0,4 & $-1,6$ \\
Estados Unidos & 1,4 & $-1,3$ & $-2,8$ \\
Zona Euro & 0,9 & $-0,9$ & $-2,6$ \\
Japón & 0,9 & $-0,9$ & $-5,8$ \\
Asia Pać́fico & 4,6 & 2,7 & $-0,2$ \\
Europa del Este & 5,6 & 3,0 & $-0,5$ \\
América Latina & 3,7 & 2,1 & 0,3 \\
& & & \\
\hline
\end{tabular}

Fuente: Consensus Forecasts de la fecha indicada.

so monetario. De este modo, aunque no podemos aislarnos de los efectos de la crisis externa, sí podemos mitigar su impacto.

En esta presentación comenzaré con una breve discusión sobre la relación entre la relajación monetaria y el origen de la crisis actual en el mundo. Luego discutiré la evolución de la inflación y de la actividad. Después me referiré a las decisiones de política monetaria, para terminar con algunas reflexiones.

\section{Sobre los orígenes de la crisis: ¿Política monetaria o regulación financiera?}

Sobre las causas de la crisis se ha escrito mucho y la verdad que ésta no es la oportunidad para revisar la multitud de factores que condujeron a ella ${ }^{1}$. Con todo, sí quisiera referirme a la interrelación entre el funcionamiento del sistema financiero y la abundante liquidez que se produjo después de las reducciones de la tasa de interés en Estados Unidos que siguieron a la caída de las acciones tecnológicas en el 2000.

Hay quienes indican como la principal causa de la crisis a la política monetaria expansiva de Estados Unidos. Ella habría originado la burbuja inmobiliaria. Sin embargo, no siempre un relajamiento de la política monetaria conduce a burbujas en los precios de los activos, o al menos a un ajuste que pueda provocar los dramáticos efectos que hemos visto en Estados

\footnotetext{
${ }^{1}$ Interesantes análisis sobre los orígenes de la crisis se pueden encontrar en los artículos recopilados en la sección I de Felton y Reinhart (2008). Para una discusión más reciente se puede ver Brunnermeier (2009) y Diamond y Rajan (2009).
} 
Unidos. Sin duda que la expansión de la liquidez fue una condición necesaria para un acelerado crecimiento del crédito, como suele suceder en períodos de relajamiento monetario. A este aumento de la liquidez se le sumaron los superávit en la cuenta corriente de los países emergentes y de los exportadores de materias primas. Asimismo, este proceso se dio en un contexto de agresivas búsquedas de retornos y de innovación financiera.

Es posible argumentar que el boom inmobiliario en Estados Unidos fue en parte causado por la relajación monetaria (Taylor, 2008). Incluso, existe evidencia de que en los países desarrollados mientras mayores son los excesos de la política monetaria, mayores son los booms inmobiliarios (Ahrend et al., 2008). No obstante, si bien es necesaria la liquidez para generar una expansión del crédito y burbujas en los precios de los activos, no es una condición suficiente para que se desarrolle una crisis de las proporciones de la que hoy enfrentamos. En los países en desarrollo sabemos muy bien que cuando a una desaceleración cíclica se le agrega una crisis financiera, sus efectos son más profundos y duraderos.

De hecho, en el mismo período, economías con el mismo grado de expansividad en su política monetaria y con aceleraciones del crédito, pero con sistemas financieros sólidos, no acumularon vulnerabilidades. Tenemos un caso muy cercano: el nuestro (Gráfico $\mathrm{N}^{\circ} 1$ ).

Entre 2001 y 2004, en Chile también hubo una fuerte reducción de la Tasa de Política Monetaria (TPM), que no produjo una burbuja en los precios de las casas ni tampoco debilitó al sistema financiero ${ }^{2}$. Por qué no se produjo una burbuja en los precios de las casas en Chile es algo que requiere de más estudio. Probablemente una mayor elasticidad de la oferta de casas puede haber contribuido a limitar el aumento de los precios (Glaeser et al., 2008). Tal vez fue la forma en que se otorgan los créditos hipotecarios, así como sus garantías, lo que evitó la formación de una burbuja. Algo que me parece una hipótesis bastante probable es que, dado el nivel de ingreso de Chile, muy por debajo de los países desarrollados, la expansión del crédito a los hogares se orienta con mayor fuerza al financiamiento de la compra de bienes de consumo durable que a la compra de viviendas. Este tema está aún abierto, pero las diferencias son notables. En todo caso éste es un área al que habrá que poner particular atención en el futuro (Gráfico $\mathrm{N}^{\circ}$ 2). Además, hubo países que tuvieron un boom inmobiliario, con precios de las casas que aumentaron muy por encima de sus fundamentales, como

\footnotetext{
${ }^{2}$ Se podría afirmar que mientras los Estados Unidos tuvieron una tasa de interés inferior a la sugerida por una regla de Taylor (como lo sugiere Taylor, 2008), en Chile eso no habría ocurrido, aunque no conozco evidencia que apoye o contradiga esta hipótesis.
} 
GRÁFICO No 1: TPM CHILE Y FED FUNDS EE.UU.

(Porcentaje)

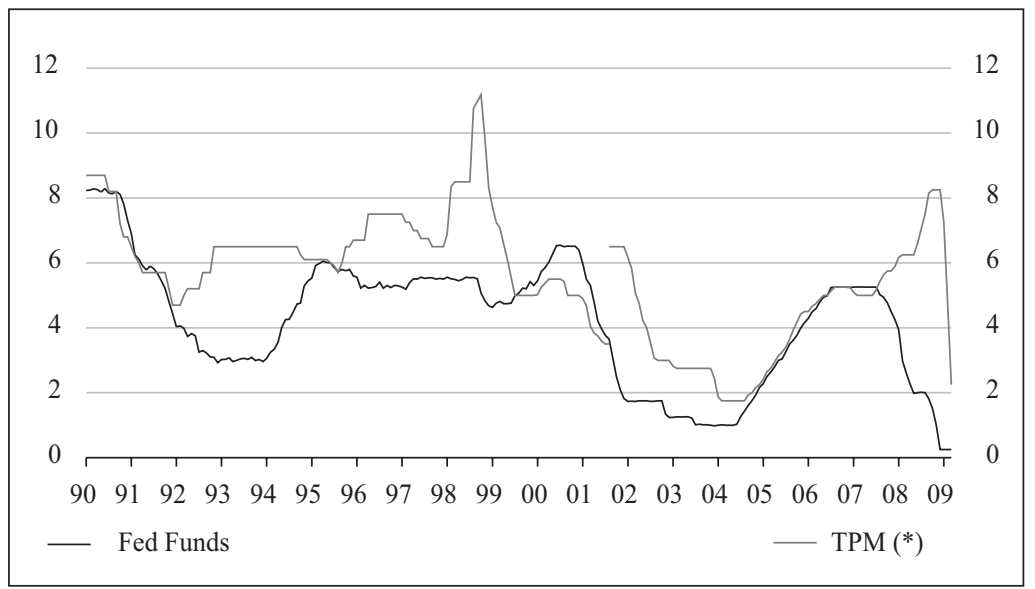

(*) A partir de agosto del 2001 la TPM corresponde a una tasa de interés nominal, previo a esa fecha corresponde a una tasa reajustable.

Fuentes: Banco Central de Chile y Reserva Federal EE.UU.

España y Australia, pero cuyos sistemas bancarios han mostrado mucho mayor resiliencia ${ }^{3}$.

En consecuencia, lo que ocurrió en Estados Unidos fue más bien una creciente fragilidad de su sistema financiero, que pasó inadvertida para el mercado y los reguladores. Hubo una deficiente evaluación de los riesgos. Se tuvo la equivocada percepción de que ellos estaban adecuadamente cubiertos y diversificados por el nuevo modelo de banca de "originar y distribuir”. Tanto la regulación prudencial como las políticas internas de evaluación de riesgo de los agentes financieros fracasaron estrepitosamente.

Esto me lleva a otro punto importante en la discusión reciente de política monetaria, el referido a si la política monetaria debiera o no tomar en cuenta los precios de los activos al momento de tomar las decisiones de tasas de interés. Si bien no se puede descartar la opción de endurecer la instancia de política monetaria ante aumentos significativos de los precios de los activos, no es seguro que estos vayan a ceder ante un aumento de la tasa de interés. Ello es particularmente importante en economías emergentes, donde una mayor tasa de interés puede incrementar los incentivos para el carry trade y exacerbar los aumentos de los precios de los activos. Para

${ }^{3}$ De acuerdo con Ahrend et al. (2008), Australia habría tenido, entre el 2000 y el 2003, una tasa también por debajo de la sugerida por la regla de Taylor. 
GRÁFICO N 2: $\quad$ PRECIOS DE LA VIVIENDA

(Índice nominal, primer trimestre $2001=100$ )

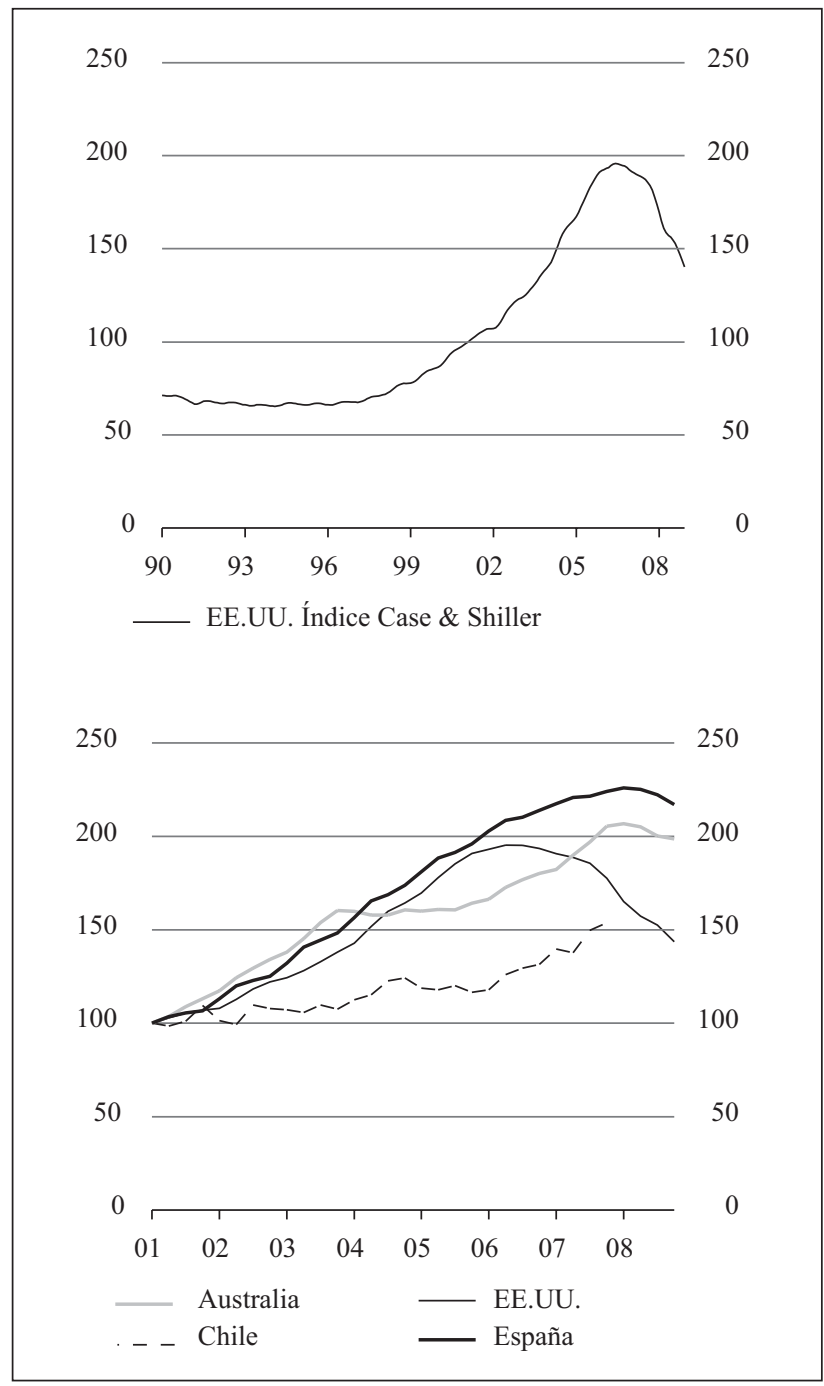

Fuente: Banco Central de Chile y Bloomberg.

evitar los desajustes financieros ante aumentos excesivos e injustificados de estos precios, la primera línea de defensa debe ser siempre la regulación financiera macroprudencial y la evaluación de los riesgos sistémicos, y no movimientos de la tasa de interés ${ }^{4}$. Tal como ya señalé, se puede tener una rápida expansión del crédito sin que esto ponga en riesgo la estabilidad

${ }^{4}$ Para más detalles sobre este tema véase De Gregorio (2008a). 
financiera. Lo que sí es nocivo y puede incentivar la creación de burbujas es el compromiso, implícito o explícito, de relajar sustancialmente la tasa de política monetaria cada vez que caen los precios de los activos, a no ser que efectivamente se evalúe que el sistema financiero está en serio riesgo.

En resumen, la abundante liquidez, inducida por una política monetaria expansiva y un aumento del ahorro en las economías emergentes, particularmente de Asia, permitió que se alimentara una burbuja inmobiliaria. Con todo, aunque fue un ingrediente de los desbalances acumulados hasta el estallido de la crisis, no fue la causa principal, la que tiene mucho más que ver con el funcionamiento del sistema financiero. Es decir, con la misma trayectoria de política monetaria y de balances globales de ahorro e inversión, un adecuado sistema de evaluación de riesgos podría haber evitado la crisis, al menos en las proporciones que ha tomado.

\section{La evolución de la inflación}

Durante gran parte de 2008 las preocupaciones sobre el escenario económico mundial se dividían entre cómo hacer frente a los primeros efectos del rompimiento de la burbuja inmobiliaria — que mayormente afectaba al mundo desarrollado- y cómo enfrentar el significativo incremento de la inflación. Desde que se inició este último proceso, en el primer semestre del 2007, argumentamos que su origen estaba ligado a factores distintos del ciclo económico interno, tales como los precios de los alimentos y combustibles en los mercados internacionales y las condiciones climáticas adversas que propiciaron aumentos significativos del costo de la energía eléctrica. Durante ese año, el precio de los alimentos no-perecibles subió 15\%, y los precios de las frutas y verduras frescas lo hicieron en más de 30\%. Esto se compara con aumentos promedio de $2 \%$ y caídas promedio de $2 \%$ anual para ambas categorías en el período 2000-2006, respectivamente. La gasolina subió $15 \%$ en el 2007 . Una característica importante de la economía chilena es que tiene pocas distorsiones en el mecanismo de fijación de precios. Ello hace que los aumentos en los precios internacionales de los bienes se transmitan con rapidez a los precios locales, algo que en muchos países se evita a través de fijaciones de precios explícitas o subsidios fiscales masi$\operatorname{vos}^{5}$ (Gráfico No 3 ).

El punto más álgido de este proceso se dio a partir de mayo de 2008. Después de cierta tranquilidad en los registros mensuales de inflación durante el primer trimestre del año pasado, se comenzaron a observar aumen-

${ }^{5}$ Para más detalles sobre el aumento de la inflación en el 2007 y su origen externo, véase De Gregorio (2008b) 
GRÁFICO N N $^{\circ}$ VARIACIÓN ACUMULADA DEL IPC POR PAÍS

(Porcentaje)

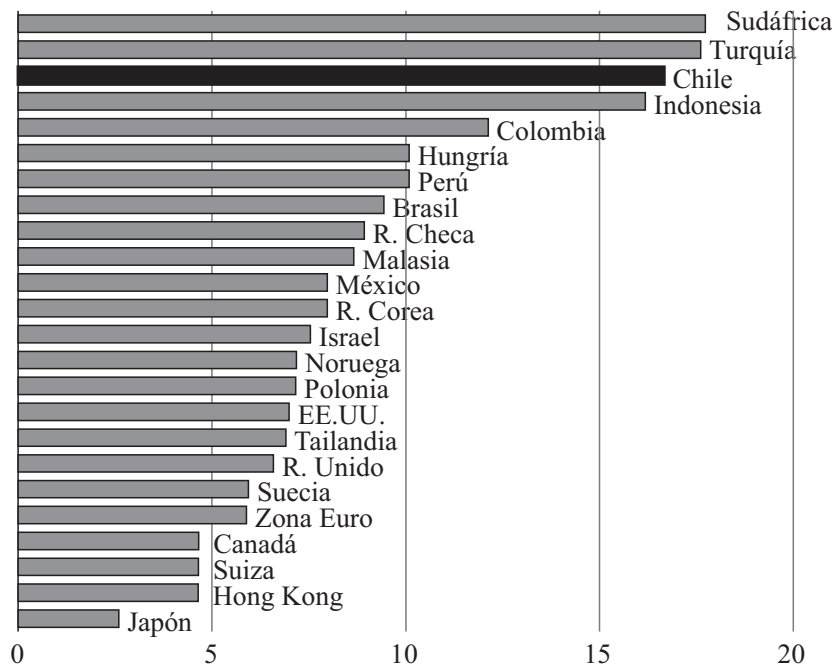

(a) Entre enero del 2007 y octubre del 2008

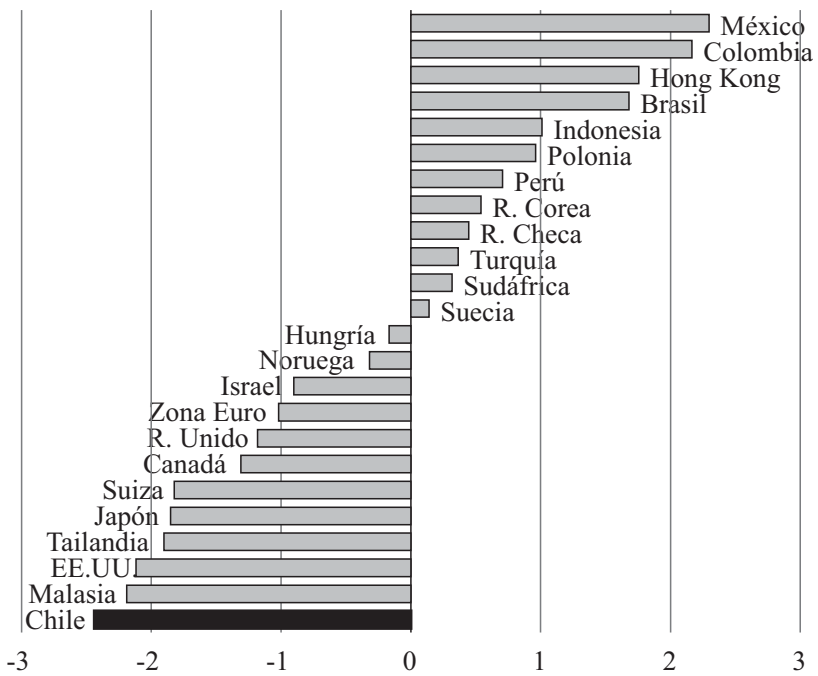

(b) Entre octubre del 2008 y enero/febrero del 2009 (*)

(*) Para Canadá, Hong Kong, Hungría, Israel, Japón, Malasia y R. Unido corresponde a datos hasta enero del 2009.

Para el resto, febrero del 2009.

Fuente: Oficinas de estadísticas de cada país. 
tos masivos e inesperados de la inflación. Tal como advertimos en dicha ocasión, se estaban generando efectos de propagación mayores que los esperados, los que ponían en riesgo la convergencia de la inflación a la meta. Las expectativas de inflación también comenzaron a aumentar. Tanto los efectos indeseados de segunda vuelta como los aumentos de las expectativas requirieron de una rápida y decidida respuesta de la política monetaria con el propósito de re-encausar la trayectoria de la inflación a su meta. Esto resultaba indispensable para evitar que la persistencia inflacionaria generara un espiral de precios y salarios que resultara muchísimo más costoso de revertir si no se tomaban medidas anticipadas. De hecho, los costos en materia de actividad hubieran sido mayores si se hubiera permitido que la inflación persistiera.

Pero el mundo cambió, y radicalmente. Lo que se esperaba fuera una mera desaceleración económica global se fue transformado en una severa caída de la actividad. Consecuentemente, los precios de las materias primas comenzaron a ceder con fuerza inusitada. Después de haber llegado a cerca de 150 dólares a mediados del 2008, el barril de petróleo retrocedió hasta 40 dólares en diciembre. Algo similar sucedió con el cobre, otros minerales, granos, etc. La respuesta de la inflación no se hizo esperar. Desde el peak inflacionario del año pasado, Chile es uno de los países donde la inflación ha caído con más fuerza ${ }^{6}$. Las expectativas de inflación también se han ajustado de manera importante ante este nuevo escenario global (Gráfico $\mathrm{N}^{\circ}$ 4).

Con todo, el punto central, en el escenario que hoy vemos como más probable, es el efecto sobre las presiones inflacionarias de la ampliación de las holguras de capacidad y la caída de los precios internacionales de los productos básicos que se está dando por el impacto de la recesión mundial. Sus efectos sobre la inflación proyectada a dos años plazo son muy relevantes y han permitido la aplicación de políticas contracíclicas. El compromiso anti-inflacionario, que surge de conducir la política monetaria sobre la base de un esquema de metas de inflación flexible, ha abierto espacios para un importante e inédito ajuste de la política monetaria. Asimismo, para que la política monetaria sea efectiva, los cambios de tasas deben transmitirse a toda la curva de retornos, y ello se logra con una política monetaria basada en un ancla creíble. De hecho, desde que el Banco Central anunció un sesgo a la baja de la TPM, el mercado comenzó a internalizar a todos los plazos este relajamiento monetario y es así como hoy día vemos que el

\footnotetext{
${ }^{6}$ Esto ocurre incluso si se descuenta el posible efecto que han tenido los cambios metodológicos en la medición del IPC.
} 


\section{GRÁFICO N ${ }^{\circ}$ 4: $\quad$ INFLACIÓN Y EXPECTATIVAS}

(Variación anual, porcentaje)

12

9

6

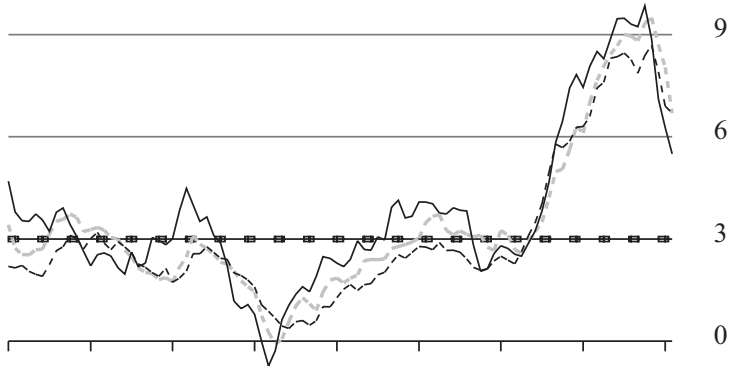

$-3$

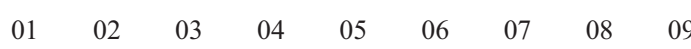

IPC

IPCX

IPCX1

8

6

4

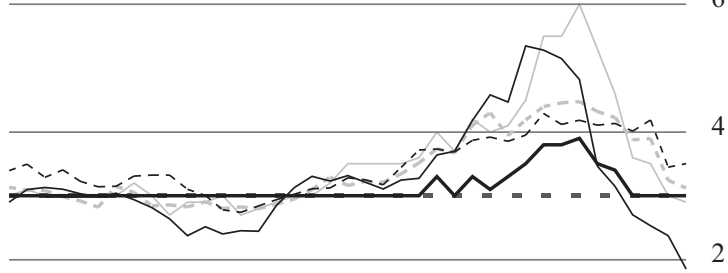

0

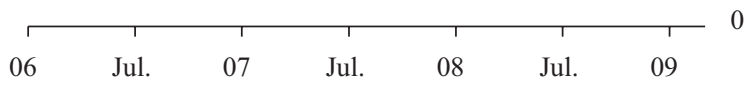

CI 1 en 1 (1)

EEE 1 año (2)

CI 3 en 2 (1)

EEE 2 años (2)

CI 5 en 5 (1)

(1) Compensación inflacionaria calculada a partir de contratos swaps.

(2) Encuesta de Expectativas Económicas del Banco Central de Chile.

Fuentes: Banco Central de Chile e Instituto Nacional de Estadísticas. 
GRÁFICO No 5: TASA DE POLÍTICA MONETARIA, TASA DE CAPTACIÓN Y CURVA FORWARD

(Porcentaje)

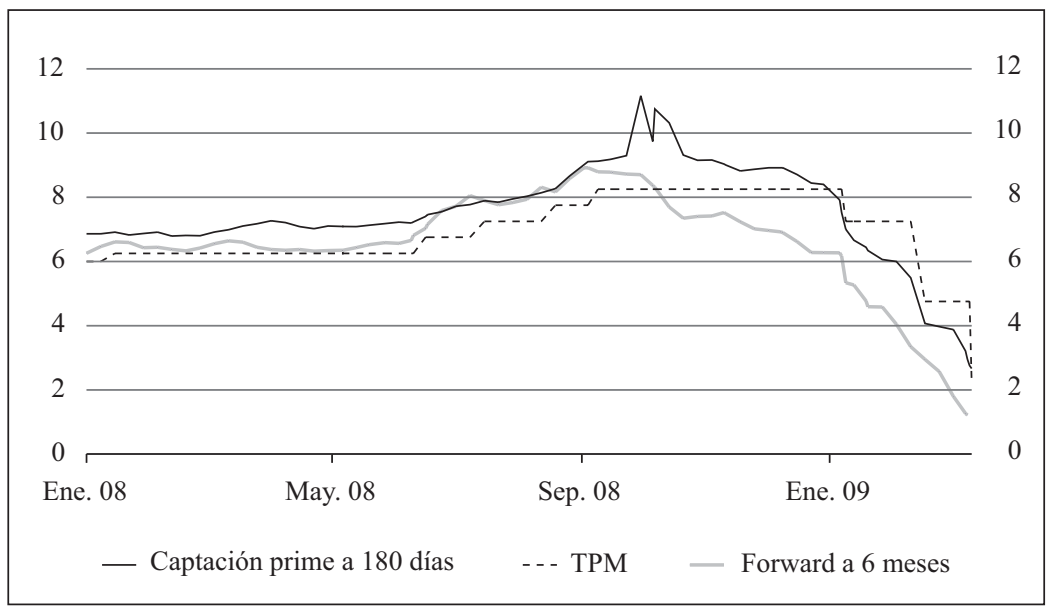

Fuente: Banco Central de Chile.

relajamiento monetario se está transmitiendo a las tasas de colocación (Becerra et al. 2009), lo que deberíamos seguir observando tras la baja de la semana pasada (Gráfico $\mathrm{N}^{\circ}$ 5).

\section{La menor actividad en Chile}

Como lo indiqué anteriormente, la menor actividad tiene importantes consecuencias sobre las perspectivas inflacionarias. Para entender dicho fenómeno es útil distinguir tres factores:

- $\quad$ Ciclo económico interno.

- Efectos reales y financieros de la crisis internacional.

- $\quad$ Crisis de confianza global.

Quiero referirme a cada uno de esos tres factores:

(i) Ciclo económico interno

La demanda interna creció aceleradamente en los últimos años. Esto no se tradujo enteramente en mayor actividad, pues parte de ella se desvió a bienes importados. En el período 2004-2007 la demanda interna creció en promedio $8,1 \%$ anual, esto es 2,9 puntos porcentuales más que el producto. 
El consumo privado, en ese mismo lapso, creció en promedio 7,2\% anual. La inversión aumentó 12,1\% promedio anual, más del doble del crecimiento del producto, lo que nos llevó a tasas de inversión récord en nuestra historia. Este proceso necesariamente debía atenuarse, tal como se comenzó a observar en el transcurso del 2008 (Gráfico $N^{\circ}$ 6). Es normal que haya cierto grado de aglomeración en las decisiones individuales de consumo e inversión, en particular cuando ellas responden a condiciones financieras y globales comunes. Algo similar debiera ocurrir en períodos de mayor debilidad.

Por lo anterior, no se puede pretender que el ciclo desaparezca o que la política monetaria lo estabilice completamente, algo que tampoco es recomendable. Las políticas macroeconómicas sólo deben aspirar a suavizar las fluctuaciones. La política monetaria, comprometida con la estabilidad de precios, sirve al propósito de estabilizar ambos, la inflación y el ciclo económico.

Hacia mediados del año pasado, se pensaba que con un escenario internacional de menor crecimiento, pero no de crisis, una política monetaria más restrictiva contribuiría a reducir las presiones inflacionarias. Esto, en el entendido de que, aunque el shock que había originado, el aumento de la inflación era externo, propiciar un menor crecimiento de la demanda interna permitiría mitigar su propagación hacia otros precios, algo que ya observábamos en los registros de inflación de parte del segundo y tercer trimestre

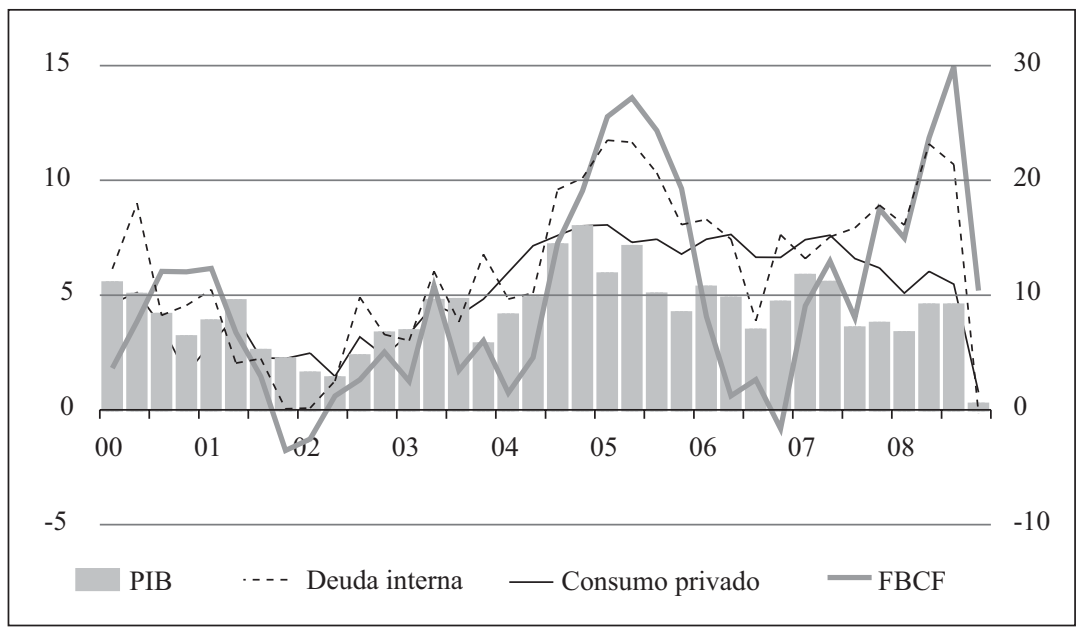

Fuente: Banco Central de Chile. 
del 2008. Sin embargo, a la evolución natural del ciclo interno ante una política monetaria más restrictiva, se le sumó una crisis internacional de proporciones. Esta crisis, tal como la observamos hoy, está teniendo un impacto sobre la actividad mayor al que preveíamos y al que era necesario para llevar la inflación a la meta, lo que ha resultado en que la política monetaria haya cambiado su signo para mitigar el negativo impulso externo.

\section{(ii) Efectos reales y financieros de la crisis internacional}

La crisis económica global tiene dos tipos de efectos a nivel interno. El primero es el financiero. Los premios por riesgo aumentan y los flujos de capital se reducen. En nuestro caso, tal como la información hasta ahora lo revela, no ha habido problemas de financiamiento externo, y de haberlos el Banco Central ha asegurado que proveerá la liquidez en dólares y pesos necesaria para que el sistema financiero siga canalizando adecuadamente el crédito. El costo promedio del financiamiento externo ha caído, aunque para algunas empresas ha subido, producto de la mayor incertidumbre global y del funcionamiento menos fluido de los mercados financieros internacionales (Gráfico $\mathrm{N}^{\circ}$ 7).

La crisis tiene también importantes ramificaciones hacia el sector real. Si bien la caída de la demanda mundial afecta a todos los países, el efecto más directo lo han sufrido las economías exportadoras de productos manufacturados — en especial maquinarias y equipos — dirigidos a países desarrollados (Gráfico $\mathrm{N}^{\circ}$ 8). Naciones como Alemania y Japón han visto un agudo efecto sobre su actividad, a pesar de que inicialmente estaban en una mejor posición que Estados Unidos.

Así, aunque la caída de la inversión y el consumo de bienes durables en el mundo tienen su impacto más directo en las economías industriales exportadoras, ello también lleva a caídas en las exportaciones de los países productores de bienes intermedios y básicos, entre ellos Chile. Sin embargo, nuestro país no se debiera ver tan afectado por una característica que siempre ha sido sindicada como un problema para nuestro desarrollo, y que yo comparto: ésta es el bajo valor agregado, o el poco contenido de capital humano, de sus exportaciones. Las exportaciones chilenas son más cercanas a productos básicos, los que presentan demandas relativamente abundantes. Siempre habrá un precio al que se podrá exportar. El principal efecto es, entonces, la caída del precio de las exportaciones, por cuanto las limitaciones a las cantidades son más escasas (Gráfico № 9). Si bien los menores precios inducen a los productores a reducir la oferta, con las consecuencias sobre el empleo, la actividad y la inversión, es muy distinto de lo que ocu- 
GRÁFICO No 7: COSTO DEL CRÉDITO BANCARIO EN EL EXTERIOR PARA RESIDENTES EN CHILE

(Porcentaje)

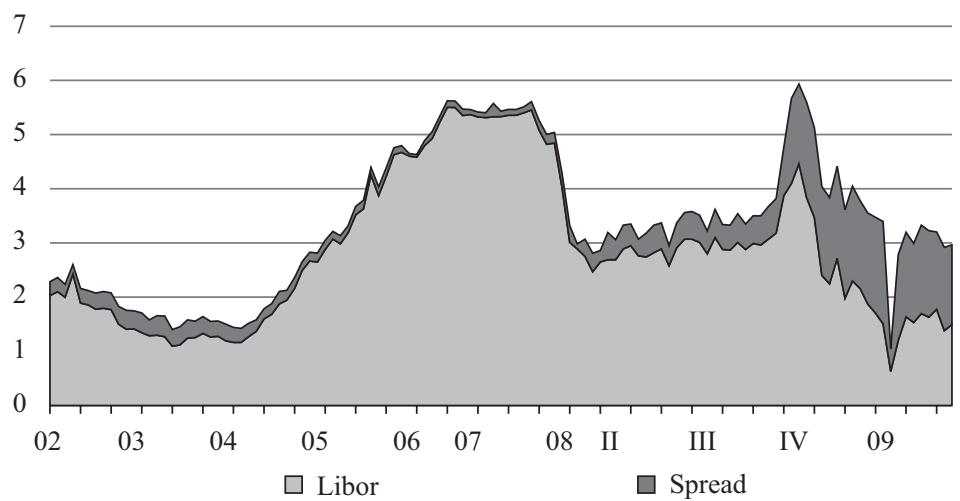

Fuente: Banco Central de Chile.

rre, por ejemplo, con un productor de bienes intermedios y específicos para la industria automotriz. Su demanda se reduce drásticamente y la producción ya iniciada termina siendo acumulada en inventarios. Y ello conduce posteriormente a la paralización de la producción. De ahí la fuerza con que la crisis está golpeando a las economías más industrializadas de Asia.

En suma, la crisis internacional tiene efectos reales sobre nuestra actividad, de manera directa en las exportaciones, pero su alcance en Chile es más limitado que en las economías exportadoras de bienes industriales.

(iii) Crisis de confianza global

A partir de septiembre del año pasado se produjo una caída de la confianza en todo el mundo (Gráfico No 10). Los hogares y las empresas, ante la elevada incertidumbre y el deterioro de las expectativas económicas, entraron en un estado de wait and see. Como es esperable en ambientes más inciertos, y en este caso extremadamente incierto, los hogares detienen abruptamente su consumo y las empresas revisan drásticamente sus planes de inversión y de producción. De ahí que la propagación de los efectos de la crisis financiera se viera agravada por una masiva pérdida de confianza. Estas pérdidas de confianza pueden conducir a procesos recesivos que son profecías autocumplidas. El público dice "la cosa viene mal, así que es mejor 


\section{GRÁFICO No 8: $\quad$ PIB Y PRODUCCIÓN INDUSTRIAL}

(Variación real anual, porcentaje)

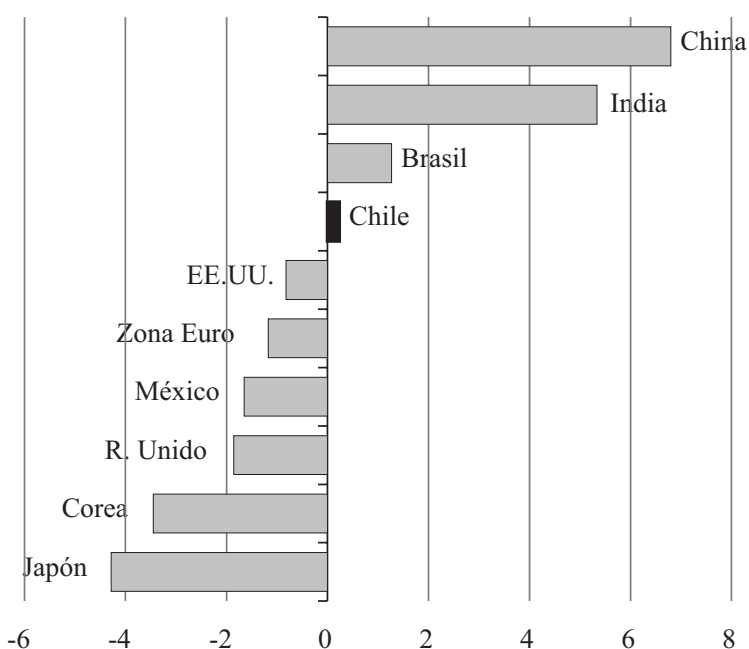

(a) Variación anual del PIB en 2008.Q4
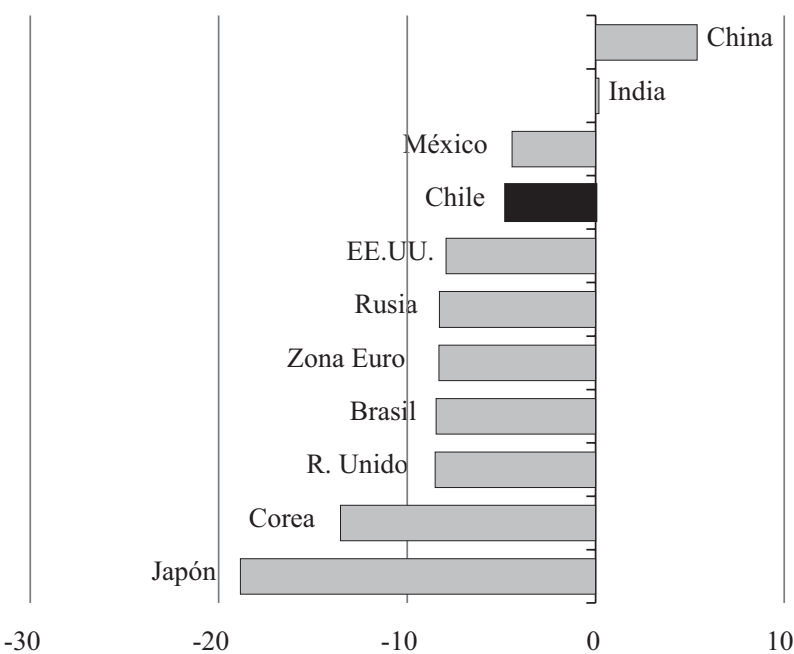

(b) Variación promedio anual de la producción industrial entre octubre del 2008 y enero del 2009.

Fuentes: Banco Central de Chile, CEIC Data y Banco Central de China. 
GRÁFICO No 9: CHILE: VOLUMEN Y PRECIO DE LAS EXPORTACIONES TOTALES

(Variación anual, porcentaje)

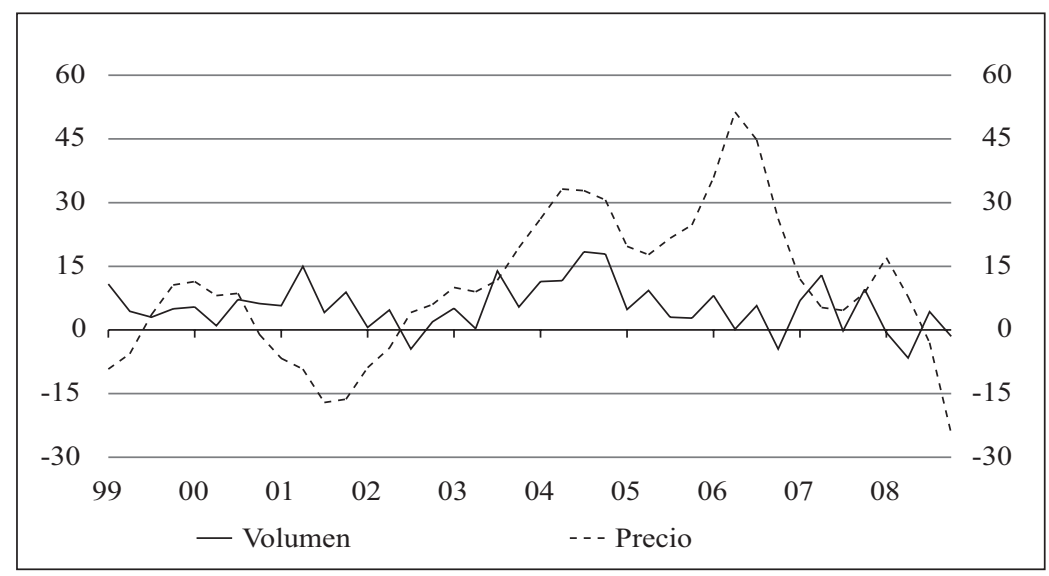

Fuente: Banco Central de Chile.

no gastar”, luego nadie gasta y al pasar el tiempo este mismo público dice "lo dije, la cosa venía mal”. No obstante, en esta ocasión, la caída de la confianza sí ha tenido base: la grave crisis en que se encuentra el mundo, aunque esta pérdida de confianza agrava sus efectos.

Las crisis de confianza son difíciles de combatir con instrumentos tradicionales de política económica. Con el pasar de los meses, con políticas macroeconómicas expansivas, creíbles y sostenibles, así como con un importante esfuerzo de comunicación objetiva sobre la realidad, los indicadores de confianza de los hogares y las empresas se deberían recuperar. En particular en Chile, donde tenemos una economía sana, políticas expansivas y el país es capaz de enfrentar el negativo escenario internacional.

En nuestro IPoM de enero, preveíamos que en el escenario más probable la economía chilena crecería entre 2 y $3 \%$ este año. En este escenario se estimó que el PIB de nuestros socios comerciales crecería $0,4 \%$, cifra que con las correcciones de los últimos meses se estima llegaría a una caída mayor a $1 \%$. Como les indiqué al comienzo, éste es un cambio de escenario no menor, que, ciertamente, afectará las proyecciones de crecimiento de nuestra economía. Aunque todos los meses realizamos ejercicios en que intentamos medir el impacto de los cambios en el entorno macroeconómico sobre nuestro propio escenario base, no contamos aún con una revisión definitiva y completa del escenario que nos permita decir, con algún nivel de probabilidad razonable, en qué orden de magnitud se encontrará el crecimiento del 2009. No obstante, no es muy difícil adivinar que éste será menor 
GRÁFICO No 10: PERCEPCIÓN ECONÓMICA

(Índices de difusión, porcentaje)

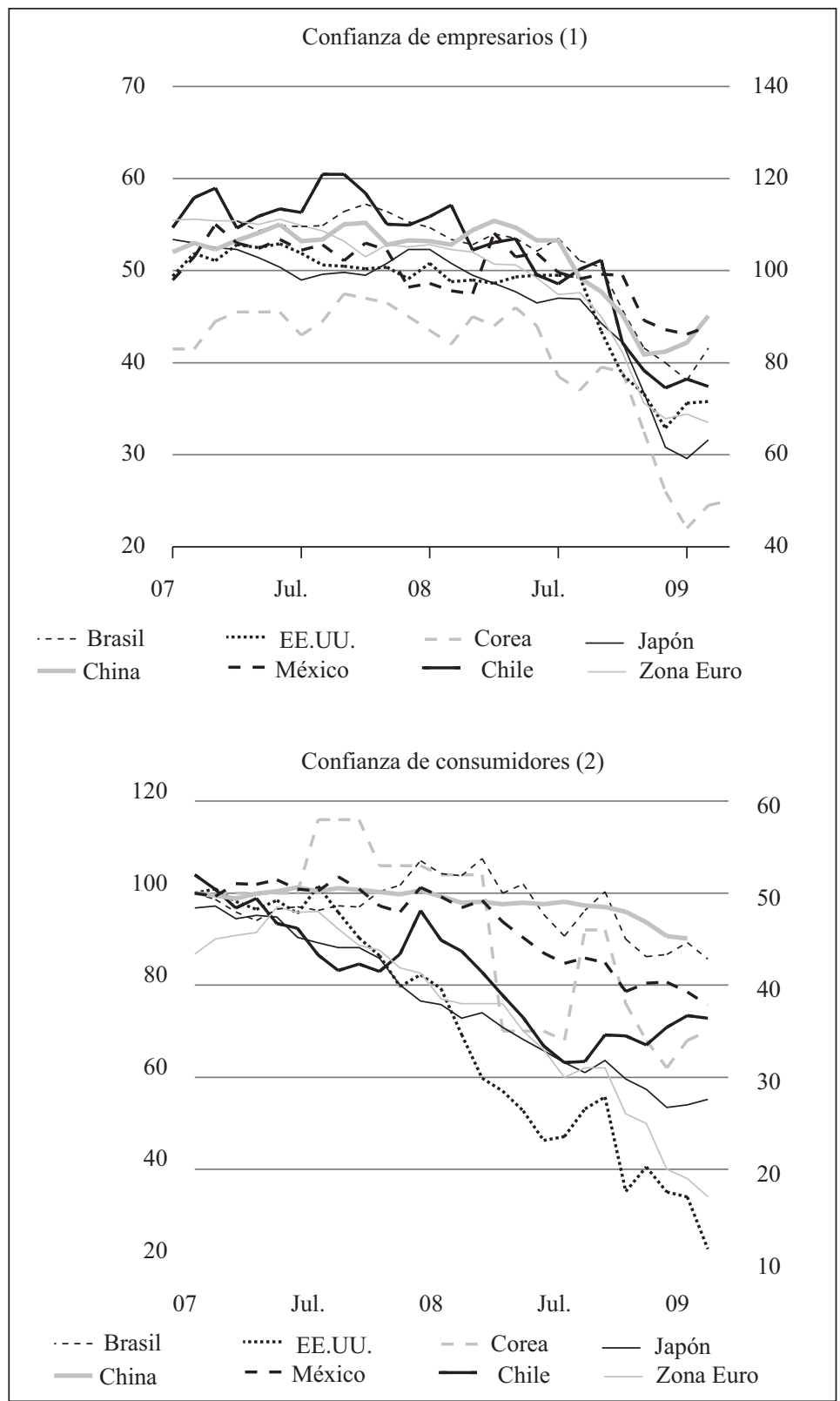

(1) Corea tiene pivote en 100.

(2) Las series de Japón, Zona Euro y Corea tienen pivote en 50. El resto de las series, son índices con base en enero 2007=100. Para Chile, se utiliza el IPEC de Adimark e IMCE de Universidad Adolfo Ibáñez/ICARE.

Fuentes: Adimark, Bloomberg e ICARE/Universidad Adolfo Ibáñez. 
que el rango de 2 a 3\% que preveíamos en enero. Cuánto, está por verse. En todo caso, puede tomarse como antecedente el cambio en las proyecciones de los analistas que responden la Encuesta de Expectativas Económicas que realiza el Banco o el último número de Consensus Forecasts. En estas proyecciones, el crecimiento previsto para este año pasó, respectivamente, de 2 y $1,9 \%$ en diciembre, a 0,2 y $0,0 \%$ en marzo.

\section{Las acciones del Banco Central en la crisis}

Desde que se inició la crisis, a mediados del 2007, las acciones del Banco Central se han focalizado en tres ámbitos:

- $\quad$ Acumulación de reservas.

- $\quad$ Provisión de liquidez en pesos y dólares.

- $\quad$ Relajamiento monetario.

El primer semestre del año pasado se produjo un inusual fortalecimiento del peso, en un contexto en que existían grandes riesgos de deterioro del ambiente financiero internacional, tal como ocurrió. Al mismo tiempo, las presiones inflacionarias habían sido relativamente acotadas durante el primer trimestre. En este escenario, el Consejo del Banco decidió fortalecer nuestra posición de liquidez internacional por la vía de acumular 8.000 millones de dólares en un período de ocho meses. Para preservar la independencia de la política monetaria, es decir, no superditarla a la política cambiaria ni a un valor determinado del tipo de cambio, se optó por una modalidad preanunciada y mecánica de compra de 50 millones de dólares diarios. De hecho, tal fue el grado de independencia, que posteriormente se pudo subir la tasa de interés ante un escenario inflacionario más complejo, sin dejar de intervenir.

A mediados de septiembre, las tensiones de liquidez en el mundo, y también en Chile, aumentaron de manera sustancial. Esto llevó al Consejo a dar término al programa de compra de reservas cuando se habían acumulado algo menos de 6.000 millones de dólares, quedando con una posición de liquidez internacional suficientemente holgada para mitigar posibles procesos de sudden stop de los flujos de capitales.

Además, ante el recrudecimiento de los problemas de liquidez, el Banco anunció la oferta de liquidez en pesos y dólares a través de repos y swaps. Posteriormente, en octubre, se amplió la gama de colaterales elegibles y se extendió el programa de swap en dólares por seis meses. Luego, en diciembre, se continuó con la ampliación de plazos, anunciando la exten- 
sión del programa de repos y swaps por todo el 2009, y volviendo a ampliar el abanico de colaterales elegibles. El propósito de estas medidas fue alinear las tasas de mercado con la Tasa de Política Monetaria (TPM) y aliviar las tensiones de liquidez en dólares. Ambos objetivos han sido cumplidos, y la escasa demanda por dólares a través de operaciones swap muestra que nuestra economía sigue con un acceso fluido a los mercados financieros internacionales. En todo caso, y para asegurar la liquidez, los instrumentos diseñados el año pasado seguirán vigentes por todo este año, y de ser necesario se ampliarán para permitir el normal funcionamiento del sistema financiero. Ello, para que éste pueda cumplir con su rol de canalización del crédito al sector privado no financiero.

Es importante destacar que para que los mecanismos de transmisión de la política monetaria funcionen adecuadamente se debe alinear el mercado monetario con la TPM. Nada se obtiene reduciendo la tasa de interés, si esto no se transmite al resto del mercado. Es por ello que, enfrentados al recrudecimiento de la crisis, la primera tarea fue aliviar las presiones de liquidez.

Con el desarrollo de la crisis, y sus consiguientes efectos sobre la inflación proyectada, se abrieron espacios para un relajamiento monetario. Éste ha sido de magnitudes muy significativas, tanto si se le compara con experiencias previas como con lo que han hecho otros bancos centrales. Durante el primer trimestre la TPM se redujo en 600 puntos base, pasando de 8,25 a 2,25\%.

Es importante volver a notar que nuestra economía no ha sufrido los problemas que han debido enfrentar otras economías en sus sistemas financieros. Por ello, la relajación monetaria en Chile no busca restablecer el funcionamiento del crédito, como puede suceder en otros países, sino que ha sido enteramente coherente con las perspectivas inflacionarias. Ello es fruto de un esquema de metas de inflación creíble, que actuó coherentemente con su objetivo cuando la inflación amenazaba con ser indeseadamente alta, y lo está haciendo con la misma coherencia cuando existen riesgos de que la inflación pueda ser indeseadamente baja.

Aunque las rebajas de la tasa de interés han tenido una intensidad no vista, su magnitud es acorde con las circunstancias. Ellas buscan mitigar los riesgos sobre la economía chilena de un deterioro prolongado de la economía mundial, lo que ha hecho que la habitual gradualidad con que se realizan los movimientos de la TPM fuera abandonada a favor de un ajuste más rápido. Además, vista la evidencia reciente, un ajuste rápido podría acelerar, más allá de lo que la magnitud de la rebaja en sí implicaría, su transmisión a las tasas de mercado, algo que además se puede haber facili- 
tado por la eliminación del impuesto de timbres y estampillas. De este modo, tal como lo señalamos en el comunicado de nuestra última reunión, hemos aproximado la TPM a un nivel que estimamos coherente con el escenario macroeconómico actual y los riesgos que enfrentamos. Sin embargo, no podemos cantar victoria, por cuanto la velocidad con la que los acontecimientos se desarrollan no permite descansar en que el trabajo ya se ha hecho. No obstante, como también señalamos en el comunicado, los eventuales ajustes a la baja de la TPM serán de una magnitud y frecuencia comparables con los patrones históricos, que distan bastante de lo que hemos visto en los últimos tres meses. En lo principal, porque es necesario darles tiempo a los mecanismos de transmisión de la política monetaria para que actúen y puedan verse en la práctica las consecuencias de las decisiones ya tomadas.

\section{Consideraciones finales}

Quisiera finalizar con algunas lecciones sobre la conducción de la política monetaria que han surgido del gran aumento de la inflación, ocurrido desde mediados del 2007, hasta la coyuntura internacional que enfrentamos hoy.

En primer lugar, más de alguna vez se destacó que Chile era uno de los países donde se había observado un mayor aumento de la inflación, más de tres veces la meta, al mismo tiempo que la tasa de interés había subido menos que en otras economías con menor impulso inflacionario. Como antes argumenté, nuestra respuesta de política fue plenamente coherente con un marco de política monetaria flexible. Conforme el shock de precios se hizo más fuerte y persistente, la política monetaria se tornó más restrictiva. Esa misma flexibilidad en el manejo de la política monetaria es la que nos permite hoy reaccionar rápidamente al fuerte deterioro en las condiciones externas. Afortunadamente nuestra economía es suficientemente sólida para absorber cambios significativos en el curso de la política monetaria, sin amenazar la estabilidad.

En segundo lugar, la dinámica inflacionaria es muy compleja y no se puede mecanizar linealmente sobre la base de la evidencia histórica. A principios de esta década, cuando la inflación se consolidaba en niveles bajos, se observó que la persistencia de la inflación había bajado sustancialmente, reduciendo el impacto de la propagación vía indexación y otros fenómenos que daban cuenta de nuestro pasado de alta inflación (García y Valdés, 2005). Con el resurgimiento de la inflación, la persistencia volvió, y se pensó que nos acompañaría por un largo tiempo, pues se consideró que la indexa- 
ción había resucitado con fuerza. No quiero descartar dicha lógica, pero hemos aprendido, y debiéramos confirmarlo con investigaciones futuras, que la persistencia no es estable y depende en gran medida del contexto global. Eso es particularmente válido en una economía de mercado, pequeña y muy abierta ${ }^{7}$.

Finalmente, quisiera hacer una reflexión sobre el desafío comunicacional que enfrentamos. No sólo debemos aplicar las políticas correctas, sino que ponerlas en el contexto adecuado. He descrito un panorama mundial muy adverso, y alguien podría cuestionar que una autoridad haga esto, pues con ello podría generar algún grado de pesimismo. Muy por el contrario, creo que, en primer lugar, hay que hablar con realismo, y desconocer lo grave de la situación mundial sería no entender lo que está pasando. La confianza se gana con sinceridad y políticas apropiadas para el momento que se vive. Hay un segundo elemento que me permite hablar con cierta libertad y crudeza: la convicción de que nuestra economía está sana y muy bien preparada en esta coyuntura, algo que no sucedió en crisis externas anteriores. Las políticas monetaria y fiscal se están utilizando con un elevado grado de expansividad, para así limitar todo lo posible los efectos de la actual crisis internacional. Ello, sin lugar a dudas, es una muy buena noticia.

\section{REFERENCIAS}

Ahrend, R., B. Cournède y R. Price (2008): "Monetary Policy, Market Excesses and Financial Turmoil”. OECD Economics Department Working Paper No 597.

Banco Central de Chile (2009): Informe de Política Monetaria, enero.

Becerra, S., L. Ceballos, F. Córdova y M. Pedersen (2009): "Evolución Reciente de las Tasas de Interés de Colocación”. Mimeo, Gerencia de División Estudios, Banco Central de Chile.

Brunnermeier, M. K. (2009): “Deciphering the Liquidity and Credit Crunch 2007-08”. En Journal of Economic Perspectives, 23(1): 77-100.

De Gregorio, J. (2008a): “Estabilidad de Precios y Estabilidad Financiera: Algunas Reflexiones en la Actual Crisis Financiera Global”. Documento de Política Económica No 28, Banco Central de Chile.

- (2008b): "Monetary Policy and Commodity Prices in Turbulent Times 2008". En Katuri Nagaswara Rao (ed.), Global Financial Markets: Managing Turbulence. The Icafai University Press.

${ }^{7}$ Se puede argumentar, tal como se hizo cuando la inflación subía, que ello era el resultado del ciclo de la demanda interna, que de crecer con fuerza se desaceleró con fuerza. No obstante, la desaceleración de la demanda está ocurriendo en todo el mundo, y la reducción de la inflación se observa con mucha mayor fuerza en Chile. Por lo tanto, estamos en presencia de factores estructurales que van más allá de los cambios en la demanda. 
Diamond, D. W. y R. Rajan (2009): "The Credit Crisis: Conjectures about Causes and Remedies”. NBER Working Paper No 14739.

Felton, A. y C. Reinhart (2008): "The First Global Financial Crisis of the $21^{\text {st }}$ Century". CEPR-Voxeu.org.

García, P. y R. Valdés (2005): "The Inflation Process in Chile: Changes and Stability”. Mimeo, Banco Central de Chile.

Glaeser, E. L., J. Gyourko y A. Saiz (2008): “Housing Supply and Housing Bubbles”. En Journal of Urban Economics, 64(2): 198-217.

Taylor, J. (2008): "The Financial Crisis and the Policy Responses: An Empirical Analysis of What Went Wrong”. NBER Working Paper No 14631. 